Case Report

\title{
Typhoid splenic abscess : a rarity in the present era
}

\author{
A Handa $^{1}$, T Rajnikanth ${ }^{1}$, M Bhartiya ${ }^{2}$, PK Sharma ${ }^{2}$, RS Negi ${ }^{1}$ \\ Sri Lankan Journal of Infectious Diseases 2015 Vol.5 (2):96-99 \\ DOI: http://dx.doi.org/10.4038/sljid.v5i2.8089
}

\begin{abstract}
Typhoid fever is a major public health problem in South East Asia and has multiple complications involving almost every major organ system of the body. Abscess of the spleen is an uncommon complication of typhoid fever in the present era due to effective use of antibiotics. It is often fatal if not recognized in time. The conventional treatment is surgical drainage of the abscess which is associated with significant morbidity. We present a case of splenic abscess due to Salmonella enterica serotype Typhi, in a previously healthy individual which was managed conservatively by percutaneous aspiration
\end{abstract}

Keywords : Splenic abscess, Typhoid fever, Percutaneous drainage

\section{Introduction}

Splenic abscess is an unusual complication of enteric fever in the post antibiotic era. The overall incidence of splenic abscesses varies from $0.14-0.7 \%$ as per various studies. ${ }^{1}$ Common causes of splenic abscess include bacterial infections, abdominal trauma, splenic infarctions, hemoglobinopathy and immune-compromised states such as HIV, organ transplants and neoplastic diseases. ${ }^{2}$ The infective diseases where splenic abscess has been reported include pneumonia, bacillary dysentery, infective endocarditis, urogenital infections, and rarely tubercular, amoebic or fungal infections. Splenic abscess may also occur following contiguous spread from peri-nephric abscess, sub-phrenic and pancreatic abscesses. ${ }^{3-6}$

The majority of typhoid splenic abscesses are solitary, but multiple abscesses occur in a small number of patients. ${ }^{7}$ Best treatment options remain unclear. Percutaneous drainage may be appropriate in some patients, but may fail in inexperienced hands and splenectomy remains the standard therapy. In general, a solitary splenic abscess can be managed with antibiotics and percutaneous drainage. However, those with multiple abscesses or thick pus with septations and those not responding to percutaneous drainage require splenectomy to prevent mortality. ${ }^{8} \mathrm{~A}$ high

${ }^{1}$ Base Hospital Delhi Cantt

${ }^{2}$ Armed Forces Medical College

Address for correspondence: Dr PK Sharma, Armed Forces Medical College,Pune-410040

Email:pksgemed@gmail.com Tele:919823071758

Received 6 June 2015 and revised version accepted 24 August 2015 
index of suspicion is required as the classical triad of fever, left upper quadrant tenderness and splenomegaly occur only in $32-50 \%$ cases. $^{2}$

We report a rare case of typhoid fever with splenic abscess in a young immune competent male who was successfully managed with antibiotics and repeated ultrasonography guided percutaneous pus drainage on three occasions .

\section{Case report}

A 20 year old male presented to a tertiary care hospital in New Delhi with continuous fever without chills and rigors and diarrhea of five days duration. He gave a history of vague left upper quadrant pain two days prior to presentation. On clinical examination, he was febrile $\left(102{ }^{\circ} \mathrm{F}\right)$, had tachycardia (pulse rate 110/min) and left upper quadrant tenderness. Laboratory tests revealed bicytopenia (TLC:3700/uL; platelet count:90,000/ul), mild transaminase elevation (AST:159; ALT:154) with normal serum bilrubin. Screen for malaria and dengue were negative. Blood culture grew Salmonella enterica subspp enterica serotype Typhi.

Ultrasonography of abdomen showed multiple heteroechoic lesions in the spleen. Contrast enhanced computerized tomography of abdomen (Fig 1) showed multiple splenic space occupying lesions (largest measuring $7.0 \times 5.8 \times 4.3 \mathrm{~cm}$ ) in the splenic parenchyma, predominantly subcapsular in location

Hemoglobin electrophoresis was normal. 2D echo showed normal valves and no vegetations. Screen for HIV was negative. He was started on intra venous ceftriaxone and $90 \mathrm{ml}$ purulent aspirate was obtained on drainage of the abscess under ultrasonography (US) guidance. The pus culture was sterile. After 5 days, the antibiotics were changed to piperacillin-tazobactam and amikacin as he continued to be febrile. Whole body positron emission tomography scan showed a hypodense, hypometabolic cystic lesion measuring $7.8 \times 6.0 \times 7.4 \mathrm{~cm}$ in the superior pole of spleen (Fig 2) with two small lesions below the abscess. There was no other area of flourodeoxyglucose (FDG) avid uptake noted. In view of persistent fever and large residual abscess despite antibiotics and US guided percutaneous drainage, the option of splenectomy was considered and discussed with the relatives. In view of his age and long term consequences of splenectomy, it was decided to adopt a spleen conserving approach and repeated

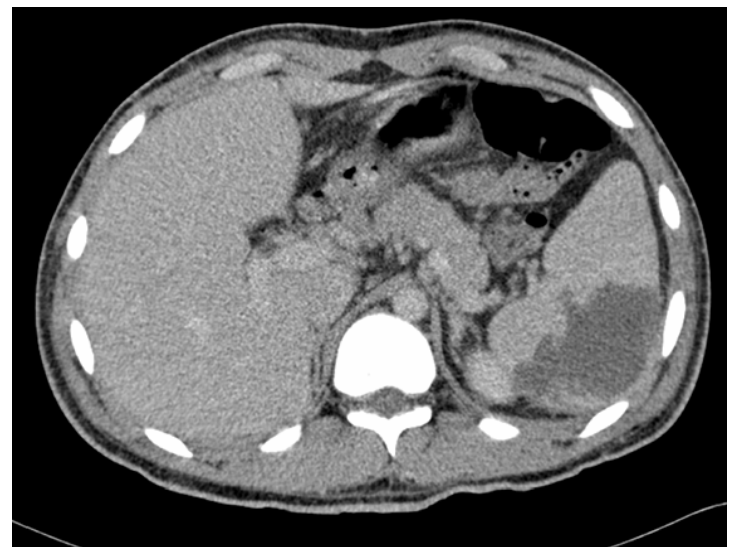

Fig 1 : CECT abdomen showing a splenic abscess measuring $7.0 \times 5.8 \times 4.3 \mathrm{~cm}$ in the superior pole of spleen

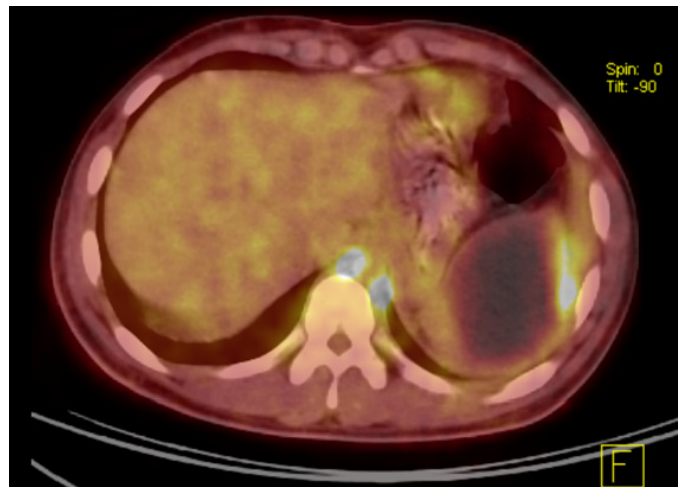

Fig 2 : FDG whole body PET scan showing a hypodense, hypometabolic lesion measuring $7.8 \mathrm{x}$ $6.0 \times 7.4 \mathrm{~cm}$ in superior pole of spleen. 
US guided aspirations were done on two occasions draining $120 \mathrm{ml}$ and $150 \mathrm{ml}$ pus on successive days. He developed a small left sided pleural effusion which resolved with treatment. The patient responded well to antibiotics and US guided percutaneous drainage and was discharged in a stable condition after three weeks. On subsequent follow up he remained asymptomatic and the US abdomen has shown no residual abscess after 3 months.

\section{Discussion}

Splenic abscess is a rare disease and is often fatal if untreated. The incidence of splenic abscess is increasing in recent times due a large number immune compromised patients and improved detection due to widespread use of sophisticated imaging modalities in diagnostic work up of patients with pyrexia of unknown origin.

Atypical manifestations of typhoid fever are being reported more often now than earlier and can occur even during the early phase of disease. ${ }^{6}$ The manifestations can be intestinal or extraintestinal with the hepato-biliary system and the spleen being among the frequent sites of abdominal salmonellosis. ${ }^{9}$ The incidence of splenic abscesses in typhoid fever decreased from $2 \%$ in the preantibiotic era to less than $1 \%$ post introduction of effective antibiotics. ${ }^{10}$ Sickle cell disease, IV drug abuse, subacute bacterial endocarditis, diabetes mellitus and immunodeficiency are common predisposing factors. ${ }^{11}$ In a series of 16 patients of splenic abscesses reported by Giovanna Ferraioli et al (2008), none of the cases were associated with typhoid fever and the most common cause was due to other bacterial pathogens. ${ }^{12}$ The severity of the infection does not appear to play a role. In up to $20 \%$ of patients with typhoidal splenic abscess, the pus is sterile while $S$. Typhi is isolated from blood culture in $40-50 \%$ of cases. The diagnosis in endemic regions therefore rests upon a high index of suspicion in individuals presenting with fever, vague left upper quadrant pain and probably a palpable mass with supporting imaging evidence of a splenic space occupying lesion with positive blood cultures. ${ }^{11}$ There have been case reports of splenic abscesses due to $S$. Paratyphi A but they are less common as compared to $S$ Typhi. ${ }^{13}$ In the past, antibiotic therapy and splenectomy were the only available treatments, both of which were associated with significant mortality. ${ }^{14}$ However, current therapeutic strategies in cases of trauma and benign splenic lesions have established spleen-preserving treatment. Thus, percutaneous drainage of splenic abscesses is being used instead of splenectomy with good results. The advantages of percutaneous drainage are a lesser risk of intra-abdominal spillage, avoidance of perioperative complications and better acceptance by the patient. ${ }^{15}$

\section{Conclusions}

Splenic abscesses are rare and these complicating typhoid are even rarer. These atypical manifestations can occur early and a high index of suspicion is required for diagnosis which can be confirmed by imaging. Treatment includes antibiotics as per sensitivity pattern of the causative agent. Splenectomy remains the mainstay of treatment in seriously ill patients, those with multiple abscesses or those not responding to medical therapy. Percutaneous drainage can be used with good results as was done in our case and should be attempted in a sub group of hemodynamically stable patients to conserve an important organ.

\section{Conflicts of interest}

All authors have nil to declare. 


\section{Funding Information}

No funds were received by any author for this case.

\section{References}

1. Chun CH, Raff MJ, Contreras L, et al. Splenic abscess. Medicine (Baltimore) 1980; 59:50-65. No doi

2. Carbonell AM, Kercher KW, Matthews BD, et al. Laparoscopic splenectomy for splenic abscess. Surg Laparosc Endosc Percutan Tech 2004; 14:289-291. doi : http://dx.doi.org/10.1097/00129689-200410000-00013

3. Chang KC, Chuah SK, Changchien CS et al. Clinical characteristics and prognostic factors of splenic abscess: a review of 67 cases in a single medical center of Taiwan. World $J$ Gastroenterol 2006; 12: 460-464 No doi

4. Chiang IS, Lin TJ, Chiang IC, Tsai MS. Splenic abscesses: review of 29 cases. Kaohsiung J Med Sci 2003; 19: 510-514 doi : http://dx.doi.org/10.1016/S1607-551X(09)70499-1

5. Chulay JD, Lankerani MR. Splenic abscess. Report of 10 cases and review of the literature. Am J Med 1976; 61: 513-522. No doi

6. Dutta T K, Beeresha, Ghotekar L H. Atypical manifestations of typhoid fever. J Postgrad Med 2001; 47:248 No doi

7. Doddaiah N, Nagaraj R, Anil Kumar MG, Murthy RS. Enteric fever complicated by multiple splenic abscesses. Ann Trop Med Public Health 2012; 5:534-6 doi : http://dx.doi.org/10.4103/1755-6783.105157

8. Shin PJ, Choi H, Bae CW et al. Percutaneous drainage of splenic abscess in typhoid fever - a case report. J Kor Med Sc 1995; 10:44-7. doi : http://dx.doi.org/10.3346/jkms.1995.10.1.44

9. Jaussaud R, Brasme L, Vernet-Garnier V, Devill JF. Splenic abscess complicating Salmonella typhi infection. Eur J Clin Microbiol Infect Dis 2000; 19:399-400 doi : http://dx.doi.org/10.1007/s100960050504

10. Nutan Narayan Bhongle, Neena Vinay Nagdeo, Vilas R. Thombare. A splenic abscess which was caused by S.typhi in a non sickler patient: A rare case finding. Journal of Clinical and Diagnostic Research 2013; 3:537-538. No doi

11. David B Huang, Herbert L DuPont. Problem pathogens: extra-intestinal complications of Salmonella enterica serotype Typhi infection Lancet Infect Dis 2005; 5:341-48. doi : http://dx.doi.org/10.1016/S1473-3099(05)70138-9

12. Giovanna Ferraioli , Enrico Brunetti, Rosario Gulizia, et al. Management of splenic abscess: report on 16 cases from a single center International Journal of Infectious Diseases 2008; 13:524-530. doi : http://dx.doi.org/10.1016/j.ijid.2008.08.024

13. Sudhaharan S, Padmaja K, Solanki R, et al. Extra-intestinal salmonellosis in a tertiary care center in South India. Journal of Infection in Developing Countries 2014; 8(7):831-837 No doi

14. Paris S, Weiss SM, Ayers WH Jr, Clarke LE. Splenic abscess.Am Surg 1994; 60:358-361 No doi

15. Loucas Thanos, Theodora Dailiana, GeorgiaPapaioannou, et al. Percutaneous CT-guided drainageof splenic abscess Am Journal Roent 2002; 179:629-632

doi : http://dx.doi.org/10.2214/ajr.179.3.1790629 